\title{
Geostatistic Approaches for Investigating of Soil Hydraulic Conductivity in Shahrekord Plain, Iran
}

\author{
M. Moradi ${ }^{1}$, D. Ghonchehpour ${ }^{1}$, A. Majidi ${ }^{1, *}$, V. Mahmoudi Nejad ${ }^{2}$ \\ ${ }^{1}$ Graduate Watershed management, Natural Resources Faculty, Hormozgan University, Iran \\ ${ }^{2}$ Graduated Geographyic Information System and Remot Sensing of Shagid Beheshti University, Iran
}

\begin{abstract}
So il hydraulic conductivity is the most important physical parameter that impresses drainage projects from technical perspective. The purpose of this study is the investigation of spatial changes of hydraulic conductivity, calibration, and feasibility of using various methods of geostatistic in Shahrekord Plain in the West of Iran. Hence Kriging (K), Inverse Distance Weighting method (IDW), Local Polynomial Interpolation (LPI) and Global Polynomial Interpolation (GPI) methods were used for interpolation. For evaluation these methods we used Cross-Validation Technique with MAE and MBE statistical criteria. Studies showed that spatial correlation of hydraulic conductivity in this region is weak and krig ing was recognized as suitable method $(\mathrm{C} 0 / \mathrm{Sill}=81 \%)$. Ordinary kriging method contains the lowest rate of MAE and MBE. In fact, the high flexibility of this method than the other methods studied shows the high accuracy of this method because of having variety models and parameters. Also results showed that ordinary kriging with a circular model are the most suitable method for interpolation in zoning the hydraulic conductivity because of lower errors and relative deviation.
\end{abstract}

Keywords Hydraulic Conductivity, Shahrekord Plain, Geostatistic, Interpolation, Iran

\section{Introduction}

The saturated hydraulic conductivity $(\mathrm{Ks})$ is of utmost importance to drainage design and affects the economic and technical feasibility of large-scale subsurface drainage projects. However, it is one of the most difficult factors to evaluate in any drain spacing equation[13]. Spatialdistributi ons of the properties of natural aquifers, such as hydraulic conductivity $(\mathrm{K})$, often exh ibit high heterogeneity. However, in a field investigation, only a small fraction of in situ data can be analysed, owing to time and cost constraints[11]. Geostatistical Tools have helped researchers in the study of the large variability that Ks often exhibit in soils[17]. Geostatistics provides a set of statistical tools for incorporat ing spatial and temporal coordinates of observations in data processing[7]. Mapping of soil attributes in unsampled areas is the main contribution of geostatistics to soilscience[ $8,6,5$ ,3]. Geostatistics provide a great aid to explore/model patterns of space/time dependences between soils data[15]. There are many studies in soil sciences that have used geostatistic $[16,14,2]$. Adhikari et al applied Ordinary Kriging techniques to characterize the spatial variation of soil texture i.e. sand and clay content on the bas is of 100 samples collected over a forest mixed agriculture farming area covering about $250 \mathrm{sq}$. $\mathrm{km}$ of Zala County in western

* Corresponding author:

Majidi_abazar@yahoo.com (A. Majidi)

Published online at http://journal.sapub.org/ajms

Copyright (C) 2012 Scientific \& Academic Publishing. All Rights Reserved
Hungary. They resulted that geostatistical techniques are useful to analyze the spatial distribution of soil texture content[1]. Moustafa et al examined that which spatial structure measure, the semi-variogram or the covariance variogram, is appropriate for inference of the spatial structure and performing interpolation of soil-water properties from sample data sets. The results showed that the covariance variogram reveals the character of spatial structure and that it is mo re appropriate for interpolation than the semi-variogram[12]. Yi Ju et al applied Kriging and cokriging methods to estimate the spatial distribution of soil properties from available large-scale survey data of Taiwan. The results suggested that by kriging and cokriging, the existing sampling density could be decreased under the large-scale sampling interval by nearly half and that sufficient spatial information about the soil properties could still be retained[21]. Irrig et al in their study showed that how kriging can improve the representation of hydraulic conductivity for subsurface drainage desins. Results showed that variations of the hydraulic conductivity were isotropic, with a high nugget effect. Kriging allowed clear identification as contour maps that could be used to determine b locks of homogeneous hydraulic conductivity[1 $0]$. Because of extensive use of geostatistic methods in soil sciences and efficiency of these methods for studying soil properties[19,9,18,20], we used Kriging (K), Inverse Distance Weighting method (IDW), Local Polynomial Interpolation (LPI) and Global Polynomial Interpolation (GPI) methods to evaluate the spatial corre lation of hydraulic conductivity of soil at Shahrekord Plain Plain. 


\section{Data and Methodology}

\subsection{Study Area}

The study plain is part of Shahrekord watershed in South west of Iran. It is located at $50^{\circ} 41^{\prime} 17^{\prime \prime}$ to $51^{\circ} 01^{\prime} 27^{\prime \prime}$ east longitudes and $32^{\circ} 07^{\prime} 02^{\prime \prime}$ to $32^{\circ} 35^{\prime} 6^{\prime \prime}$ north latitudes with about 58461 hectare and Geology of the Cretaceous limestone formation located on alluvial deposits and include old, new and old terrace deposits is related to the Quaternary. Figure (1) shows location of Shahrekord plain.

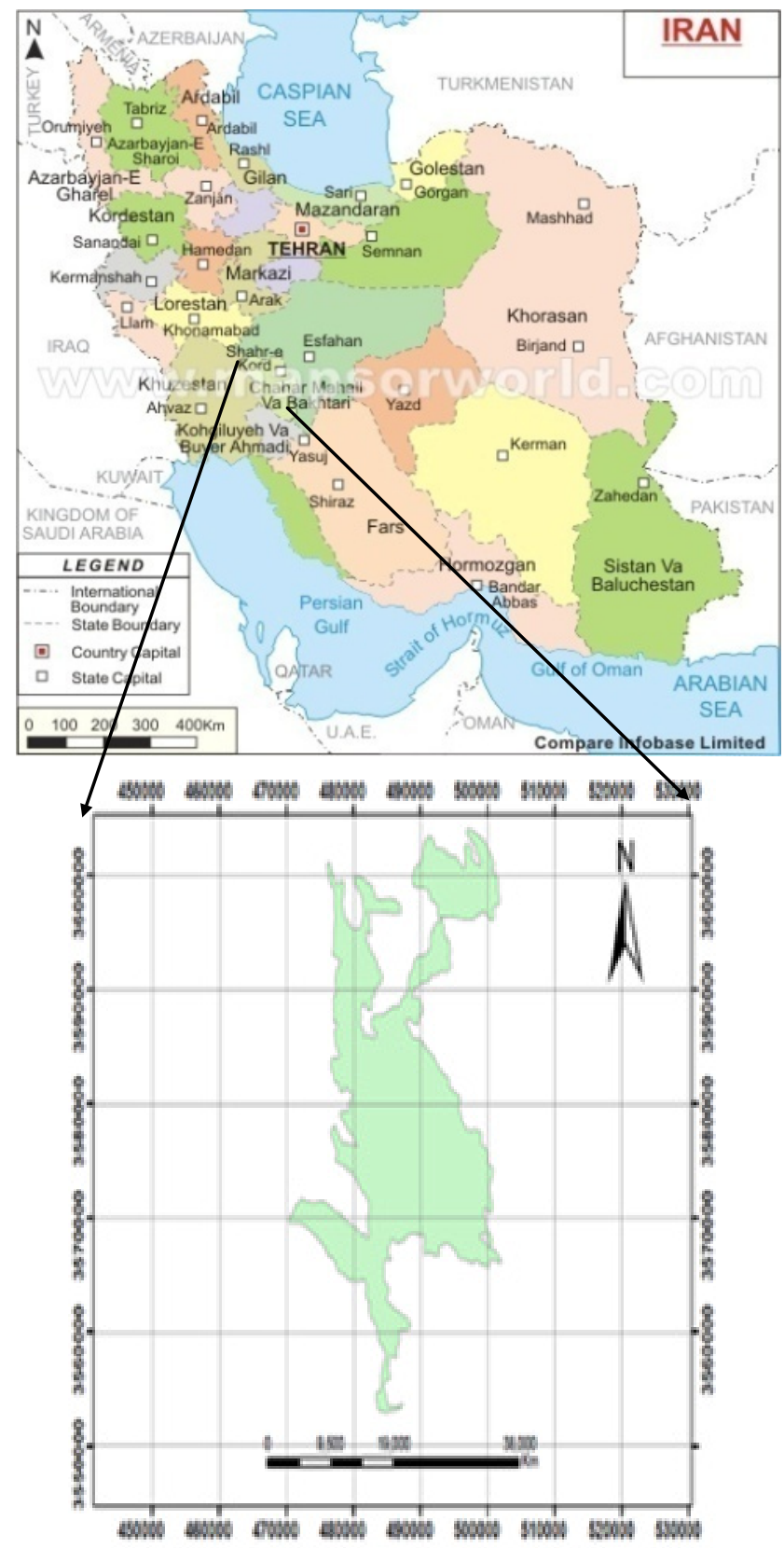

Figure 1. Shahrekord plain location (Shahrekord province)

\subsection{Study Method}

In this study the 524 wells hydraulic conductivity data of Shahrekord Plain are used as statistics references. After preparing reference maps like geology, pedology and topography map in 1:50000 scales, spatial variety of hydraulic conductivity investigate with different methods of internolation. Point data extend to area data with ordinary Kriging, $I D W^{1}$, LPI ${ }^{2}$, GPI ${ }^{3}$ Methods and ArcGIS9.3 Software. Then different methods evaluate with cross validation technique and $\mathrm{MAE}^{4}$ and $\mathrm{MBE}^{5}$ Criteria. And finally hydraulic conductivity was provided. For importance of Krig ing, its properties are described in paper.

\subsubsection{Krig ing}

Presentation errors map and variance reduction in weighting for estimating is the benefits of Kriging against others interpolation methods. Errors in this method are independency from variable and dependent to spatial location and it cause to predict the best location sampling is possible. Variogram relationship based on the measured points is as follows:

$$
\gamma(h)=\frac{1}{2 n(h)} \sum_{i=1}^{n(h)}[z(x+h)-z(x)]^{2}
$$

$\gamma(h)$ : is the variogram for a distance (lag) $h$ between observations $z(x)$ and $z(x+h) . n(h)$ : is the number of pairs of observations which are at distance $h . z(x)$ : the observed variable. $\mathrm{z}(\mathrm{x}+\mathrm{h})$ : the obs erved variable is the $\mathrm{h}$ distance from $\mathrm{z}(\mathrm{x})$ and variogram $\gamma(h)$.

Variogram is similar to variance in classic statistic but against variance that is around average, variogram show two samples differences. The main purpose of variogram calculating is investigating variability of variable ratio distance of place or time. For this reason, is necessary to draw a graph with summary of mean square differences of pair points that located at $\mathrm{h}$ as $\mathrm{x}$ axis. Figure (2) shows variogram indexes.

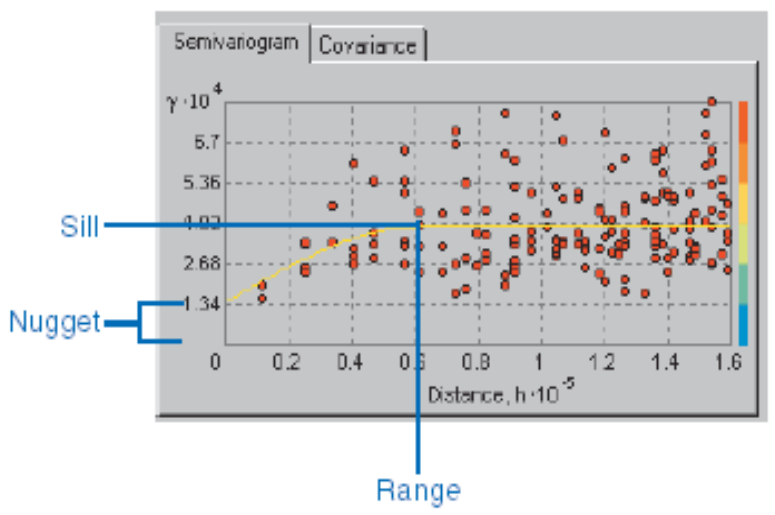

Figure 2. Components of variogram

Nugget: theoretically, at zero separation distance (i.e., lag $=0$ ), the semivariation value should be zero. However, at an infinitesimally small separation distance, the difference between measurements often does not tend to zero. This is

\footnotetext{
1 - Inverse Distance Weights

${ }^{2}$ - Local Polynomial Interpolation

3 - Global Polynomial Interpolation

4 - Mean Absolute Error

5 - Mean Bias Error
} 
called the nugget effect. The nugget effect can be attributed to measurement errors or spatial source of variation at variation at distance smaller than the sampling interval (or both): Measurement error occurs because of the error inherent in measuring devices.

Range: in model of a semivariogram, a certain distance that model level out. The distance where the model first flattens out is known as the range are spatially autocorrelated.

Sill: The value that semivariogram model attains at the range (the value on the y-axis) is called the sill. The partial sill is the sill minus the nugget.

\subsubsection{Validation}

Cross-validation consists of removing data, one at a time, and then trying to predict it. Next, the predicted value can be compared to the actual (observed) value to assess how well the prediction is working. In this research $\mathrm{MAE}$ and $\mathrm{MBE}$ are used to evaluate predicted value with ord inary Kriging and local interpolation methods that are calculated with below functions:

$$
\begin{aligned}
M A E & =\frac{\sum_{i=1}^{n}\left|z^{*}(x i)-z(x i)\right|}{n} \\
M B E & =\frac{\sum_{i=1}^{n}\left(z^{*}(x i)-z(x i)\right)}{n}
\end{aligned}
$$

Where $z^{*}(x \boldsymbol{i})=$ predicted value in xi point and $z(x \boldsymbol{i})$ $=$ actual value in xi point and $n=$ number of observations.

With the least quantity of two indexes, accuracy increase. Whatever the value of these two factors is less, the accuracy of method is more. Theoretically, whenever these factors are equal zero, the accuracy of method is $100 \%$ and estimated value of a quantity is exactly equal to its actual value.

\section{Results and Discussion}

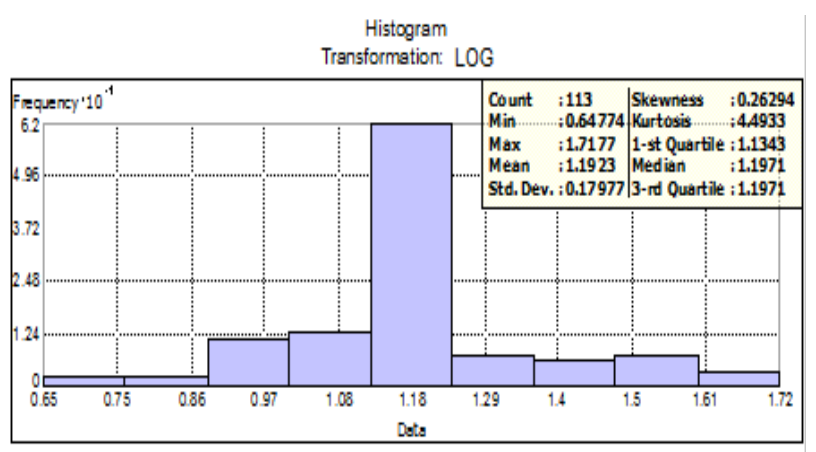

Data Sour ce: logs hahrek ord2 Attribute: log

Figure 3. Data log histogram of hydraulic conductivity

The first step in using geostatistic method is investigation of the spatial structure of the data by analysing semivariogram. Normalizing the data is the condition of using this analysis. By investigating two methods of QQPlot and data histogram specified that the data are not normal. Therefore, the data transferred to data log by means of that the data follow from normal distribution. Data histogram graph after converting logarith mic showed in figure (3).

Considering above histogram, data mean and median are very close $($ mean $=1.1971$, median $=1.1923)$. Therefore, the data with converting logarithmic were converted to normal distribution.

In Kriging method, different models such as Circular, Spherical, Exponential, Gaussian being used. Therefore with using ArcGIS9.3 software, different kind of models was checked and finally circular model was selected because of having the least errors. The properties of circular model showed in table (1).

Table 1. The properties of circular model of hydraulic conductivity semivariogram

\begin{tabular}{ccccccc}
\hline Model & $\begin{array}{c}\text { Trend } \\
\text { type }\end{array}$ & $\begin{array}{c}\text { Sector } \\
\text { type }\end{array}$ & $\begin{array}{c}\text { Range } \\
(\mathrm{m})\end{array}$ & $\begin{array}{c}\text { Nugget } \\
(\%)\end{array}$ & $\begin{array}{c}\text { Partial } \\
\text { sill } \\
(\%)\end{array}$ & $\begin{array}{c}\overline{\text { Sill }} \\
(\%)\end{array}$ \\
\hline Circular & Const & $\begin{array}{c}\text { Four } \\
\text { and 45 } \\
\text { degree }\end{array}$ & 95526 & 12.95 & 15.9 & 81 \\
\hline
\end{tabular}

The results of evaluation of different approaches of interpolation showed in table (2). Comparing these methods show that ordinary Kriging has the best accuracy (MAE=3.05 $\mathrm{m} /$ day) and the least standard deviation $(\mathrm{MBE}=0.008 \mathrm{~m} /$ day $)$. Further after ordinary Kriging, IDW has the best accuracy but it has partly $h$ igh standard deviation $(\mathrm{MBE}=0.127 \mathrm{~m} /$ day $)$. Also GPI after ordinary Kriging have the least standard deviation.

Table 2. Results of various geostat ist ic methods

\begin{tabular}{ccc}
\hline MBE & MAE & Methods \\
\hline 0.127 & 3.052 & $(I D W)$ \\
0.507 & 3.40 & $(L P I)$ \\
$0.029-$ & 3.282 & $(G P I)$ \\
$0.008-$ & 3.05 & ) OKI \\
\hline
\end{tabular}

Figure (4) shows Semivariogram of hydraulic conductivity. With attention to that it is recognized that with Nugget $=12.95$ and partial sill $=15.9 \%$, semivariogram model error $(\mathrm{C} 0 / \mathrm{Sill})$ is $81 \%$.

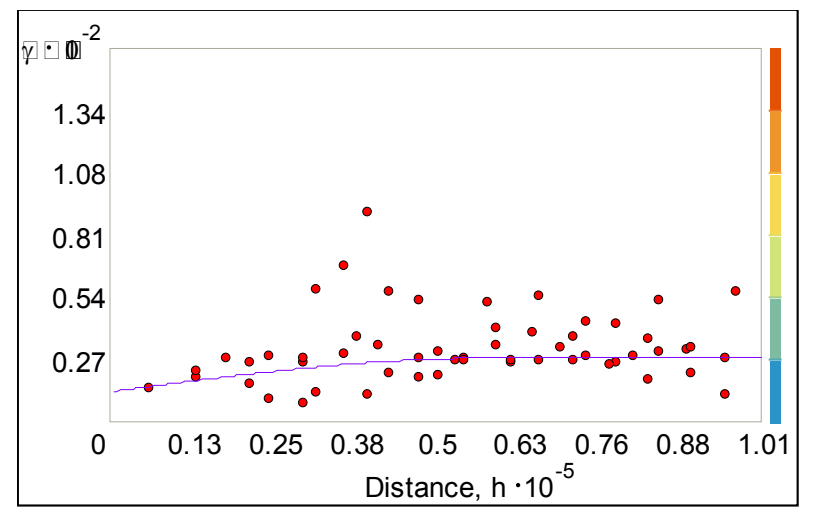

Figure 4. Semivariogram of hydraulic conductivity

As regards if $\mathrm{C} 0$ / Sill proportion be less than 0.25 , desired variable will show strong spatial correlation. Between $0.25-0.75$, medium spatial correlation and more than 0.75 , 
weak spatial correlation[18]. Therefore, in study plain, soil hydraulic conductivity shows weak spatial correlation. With this result, hydraulic conductivity map for study area was produced and shown in figure (5).

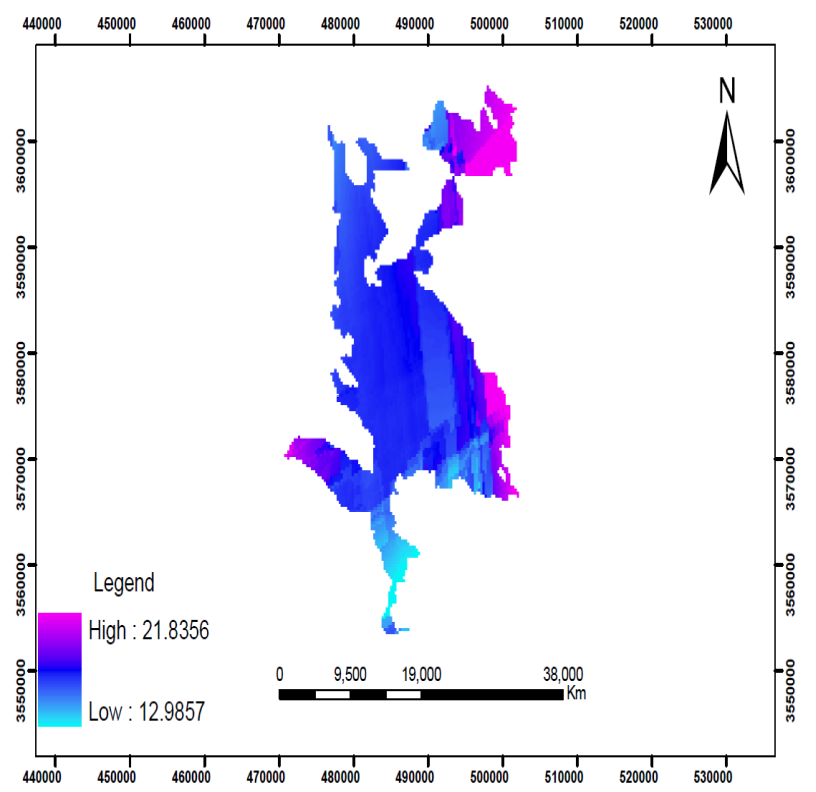

Figure 5. Mapping of Soil hydraulic conductivity in Shahrekord Plain

\section{Conclusions}

Evaluation of various interpolation methods show that Semivariogram of hydraulic conductivity in Shahrekord Plain follow from circular model. A lso results of table (2) show that between all the interpolation methods that were used in this research, ordinary Kriging has the least error and standard deviation. In the other hand IDW has good accuracy but it has partly high standard deviation. In Kriging method estimation variance is minimum and also using various models of semivariogram in this method show its high flexibility. Based on this, hydraulic conductivity map in Shahrekord plain by using of ord inary kriging method was produced (figure 5). Generally semivariogram analysis results showed weak spatial correlation for studied plain hydraulic conductivity. Climatic and hydrogeology conditions and soil youth may be the basic factors of hydraulic conductivity spatial correlation weakness [4]. Heterogeneous of region and soil structure can be the most important of weak spatial correlation of soil hydraulic conductivity in this region. This research results corresponds with results of studies such as Rogers et al[19] and Hosseini et al[9] based on lack of spatial correlation of soil hydraulic conductivity.

Region conditions (climate, hydrology and hydrogeology) have significant influence on spatial correlation of various geostatistic methods and in geostatistic methods analysis, knowledge of desired watershed base on mentioned conditions can be helped us in interpretation of various geostatistic methods results. We offer with regard to soil hydraulic conductivity depends on several factors, If possible, these factors also are used as auxiliary variables.

\section{REFERENCES}

[1] Adhikari K, Guadagnini A, Toth G, Hermann T, "Geostatistical analysis of surface soil texture from Zala county in western Hungary", International Symposium on Environment, Energy and Water in Nepal: Recent Researches and Direction for Future, pp. 219-224, 2009.

[2] Barcae E, Passarella G, "Spatial evaluation of the risk of groundwater quality degradation: Acomparison between disjunctive kriging and geostatistical simulation", Journal of Environmental Monitoring and Assessment, Vol.133, no.1-3, pp.261-273, 2008.

[3] Costa A, Durao R, Soares A, Pereira M J, "A geostatistical exploratory analysis of precipitation extremes in southern Portugahl", Statistical journal, Vol.6, no.1, pp.21-32, 2008.

[4] Delbari M, Khay iatkholghy M, Mahdian M H, "Geostatistical evaluation methods in estimate hydraulic conductivity of soil and water in the back slope areas of low water Sistan Plain", Journal of Agricultural Sciences, Vol.35, no.1, pp.1-12, 2002.

[5] Fernandez C, Bravo J, "Evaluation of diverse geometric and geostatistical estimayion methods applied to annual precipitation in Asturias (NW Spain) ", Natural resources Research, vol.16, no.3, pp.209-218. 2007.

[6] Fiorucci P, La Barbera P, Lanza L G, Minciardai R, "A geostatistical approach to multisensory rain field reconstruction and downscaling", Hydrology \& earth system sciences, Vol.5, no.2, pp.201-213, 2001.

[7] Goovaerts p, "Geostatistics in soil science: state-of-the-art and perspectives", Geoderma, Vol. 89, no.1-2, pp.1-45, 1999.

[8] Goovaerts P, "Geostatistical approaches for incorporating elevation into the spatial interpolation of rainfall", Journal of hydrology, Vol.228, no.1-2, pp.113-129, 2000.

[9] Hosseini E, Gallichand J, Caren J, "Comparison of several interpolators for smoothing hydraulic conductivity data in south west Iran", Transactions of the ASAE, Vol.36, no.6, pp.1687-1693, 1993.

[10] Irrig J, Gallichand J, Prasher S O, Broughton R S, Marcotte D, "Kriging of Hydraulic Conductivity for Subsurface Drainage Design", Journal of irrigation and drainage engineering, Vol.17, no.5, p.1-15, 1991 .

[11] Jang C S, Liu C W, "Geostatistical analysis and conditional simulation for estimating the spatial variability of hydraulic conductivity in the Choushui River alluvial fan, Taiwan", Hydrological Processes, Vol.18, no.7, pp.1333-1350. 2004.

[12] Moustafa M M, Yomota A, "Use of a covariance variogram to investigate influence of subsurface drainage on spatial variability of soil-water properties", Agricultural Water management, Vol.37, no.1, pp.1-19, 1998.

[13] Moustafa M M, "A Geoststistical approach to optimize the determination of saturated hydraulic conductivity for large-scale subsurface drainage design in Egypt", Agricultural water Management, Vol.42, pp.291-312. 2000.

[14] Naoum S, Tsanis L K, "Ranking spatial interpolation 
techniques using a GIS-based DSS", Global Nest, Vol.6, no.1, pp.1-20, 2004.

[15] Navarro-Pedreno J, Jordan M M, Melendez-Pastor I, Gomez I, Juan P, "Estimation of Soil Salinity In Semi-Arid Land Using a Geostatistical Model", Land Degradation \& Development, Vol.18, pp.339-353, 2007.

[16] Phillips D L, Dolph J, Marks D, "A comparison of geostatistical procedure for spatial analy sis of precipitation in mountainous terrain", Agricultural \& forest meteorology, Vol.58, no.1-2, pp.119-141, 1992.

[17] Regalado C M, Muñoz-Carpena R, "Estimating the saturated hydraulic conductivity in a spatially variable soil with different permeameters: a stochastic Kozeny-Carman relation", Soil \& Tillage Research, Vol.77, no.2, pp.189-202, 2004.
[18] Robinson T P, Metternicht G, "Testing the performance of spatial interpolation techniques for mapping soil properties", Computer \& Electronics in Agriculture, Vol.50, no.2, pp.97-108, 2006.

[19] Rogers J S, Selim H M, Carter C E, Fouss J L, "Variability of auger hole hydraulic conductivity values for a commerce silt loam", Transaction of the ASAE, Vol.34, no.3, pp.876-881, 1991.

[20] Taghizadeh Mehrjerdi R, Zareian M, Mahmodi S H, Heidari A, "Spatial distribution of groundwater quality with geostatistics (Case study: Yazd-Ardakan plain) ", World Applied Science Journal, Vol.4, no.1, pp.9-17, 2008.

[21] Yi-Ju C, Dar-Yuan L, Horng-Yuh G, Kun-Huang H, "Geostatistical Analysis of Soil Properties of Mid-West Taiwan Soils", Soil Science, Vol.162, no.4, pp.291-298. 1997. 